\title{
Urea Nitrogen Measurement
}

National Cancer Institute

\section{Source}

National Cancer Institute. Urea Nitrogen Measurement. NCI Thesaurus. Code C125949.

The determination of the amount of urea nitrogen present in a sample. 